14

\title{
Атомно-силовая микроскопия набухания и упрочнения закрепленных на подложке интактных эритроцитов
}

\author{
(C) М.М. Халисов, ${ }^{1,2}$ К.И. Тимощук, ${ }^{2}$ А.В. Анкудинов, ${ }^{2,3, \text { Т T.Е. Тимошенко }}{ }^{1}$ \\ ${ }^{1}$ Институт фризиологии им. И.П. Павлова РАН, \\ 199034 Санкт-Петербург, Россия \\ 2 Университет ИТМО, \\ 197101 Санкт-Петербург, Россия \\ ${ }^{3}$ Физико-технический институт им. А.Ф. Иоффре РАН, \\ 194021 Санкт-Петербург, Россия \\ ฯe-mail: alexander.ankudinov@mail.ioffe.ru
}

(Поступило в Редакцию 5 апреля 2016 г.)

С помощью атомно-силовой микроскопии в режиме поточечных измерений силового взаимодействия проведено количественное картирование наномеханических свойств интактных эритроцитов крыс в условиях, приближенных к физиологическим. Установлено, что эритроциты, закрепившиеся на подложке, обработанной полилизином (poly-L-lysine), имеют преимущественно плоскую форму. Однако со временем клетки могут скачкообразно трансформироваться в полусферические объекты, увеличиваясь в объеме и одновременно упрочняясь. Обсуждается возможный механизм эффекта.

DOI: $10.21883 /$ JTF.2017.02.44139.1840

Деформируемость эритроцитов ключевым образом влияет на реологические свойства крови. Нарушение кровоснабжения тканей часто вызвано ухудшением способности этих клеток к деформации. Важный количественный параметр - это величина модуля Юнга эритроцитов, от которой существенно зависит текучесть крови, особенно по капиллярному руслу. Источником ценной информации об эритроцитах может стать атомно-силовая микроскопия (АСМ) [1]. В частности, существует режим поточечного картирования наномеханических свойств по особенностям силового взаимодействия (PeakForce QNM, Bruker), который одновременно с рельефом поверхности позволяет изучать вариации упругого модуля Юнга и такие неупругие свойства, как сила адгезии и диссипация энергии, характеризующие локальное взаимодействие АСМ зонда с клеткой.

Бо́льшая часть АСМ исследований проводится на высушенных или химически обработанных эритроцитах [2-4]. Такой подход позволяет сделать объекты тверже, жестко закрепить их на подложке и существенно облегчает АСМ измерения, но закрывает доступ к свойствам, присущим только живым клеткам. Лишь небольшая часть работ посвящена АСМ изучению интактных эритроцитов в физиологически адекватных условиях [5-8].

Для АСМ измерений принципиально необходимо осадить клетки из физиологического раствора (ФР) на твердую подложку. Прикреплению эритроцитов способствует тонкий слой полилизина на подложке [5-8]. В работах [6-8] сравнивался модуль Юнга интактных эритроцитов от людей, здоровых и имеющих различные патологии. Докладывалось, что сахарный диабет и серповидно-клеточная анемия сопровождаются увеличением среднего модуля Юнга клеток. Прикрепленное состояние для эритроцитов, однако, не является естественным. Из-за экстремальной способности клеток к деформации можно ожидать изменений в их форме и механических свойствах по сравнению со свободными эритроцитами в кровеносной системе живого организма. В АСМ исследовании [9] сообщалось, что интактные эритроциты демонстрировали на подложке необычную, распластанную плоскую форму, что связывалось с возросшим натяжением мембраны клетки, реагирующей на контакт с полилизином. Отмечалось [10], что на подложках, обработанных концентрированным раствором полилизина, провоцируется разрыв мембраны и лизис эритроцитов. Если же брать разбавленный раствор с концентрацией менее $1 \mathrm{mg} / \mathrm{ml}$, то покрытие подложки полилизином становится не сплошным, и падает надежность иммобилизации эритроцитов. В итоге оптимизация обработки по времени экспозиции, концентрации, молекулярной массе полилизина и другим параметрам оказывается довольно тонкой процедурой. Критериями оптимизации представляются стабильность и повторяемость результатов АСМ исследования живых клеток. В такой связи в настоящей работе изучалось влияние продолжительности контакта обработанной полилизином подложки с интактными эритроцитами на характерную морфологию и среднее значение модуля Юнга клеток.

C помощью режима PeakForce QNM на атомносиловом микроскопе Bruker Bioscope Catalyst изучались интактные эритроциты крыс линии Wistar. ACM эксперименты проводились в жидкости при постоянной температуре $37^{\circ} \mathrm{C}$. Для приготовления образцов у наркотизированных самцов крыс брали кровь из брюшной аорты. Сразу после забора крови эритроциты выдерживали в пробирке для осаждения в гравитационном поле, 


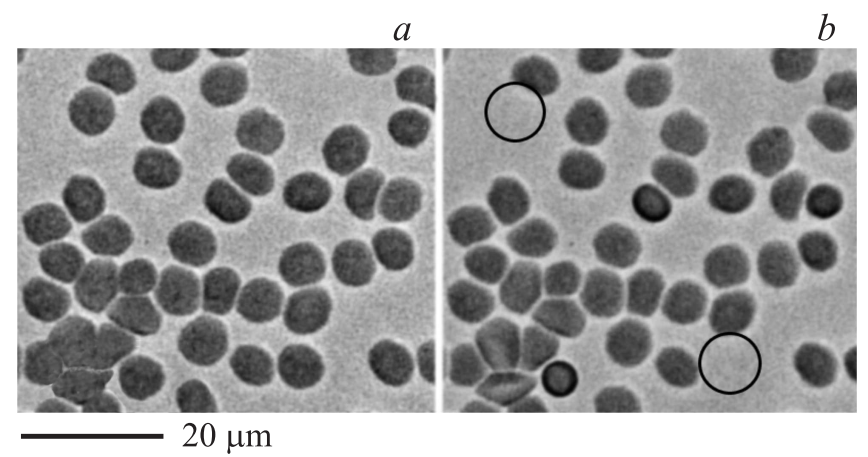

Рис. 1. Оптические изображения эритроцитов на полилизиновой подложке в изотоническом физиологическом растворе: $a-$ сразу после установки образца, $b-$ через $1.5 \mathrm{~h}$. Кружками на $b$ отмечены оптически прозрачные трансформировавшиеся эритроциты.

удаляли плазму, промывали клетки ФР с рН 7.4. Каплю суспензии эритроцитов в ФР (в соотношении 1:50) наносили на дно чашки Петри, предварительно обработанное в водном растворе полилизина $(10 \mu \mathrm{g} / \mathrm{ml}$, использовался poly-L-lysine, молекулярная масса $150-300 \mathrm{kDa}$, Sigma P8920). В чашку с эритроцитами добавляли $1 \mathrm{ml}$ ФР, ждали $20 \mathrm{~min}$, чтобы клетки смогли осесть на ее дне, затем удаляли слабо закрепленные объекты, несколько раз обновляя ФР. Выбор области исследования осуществлялся через инвертированный оптический микроскоп Carl Zeiss Axio Observer, совмещенный с ACM. В процессе АCM сканирования одновременно определялись топография подложки с эритроцитами и карта значений модуля Юнга. Модуль Юнга вычислялся по модели Снеддона [11.12] путем автоматической математической обработки силовых кривых, регистрируемых при каждом касании образца зондом.

Измерения осуществлялись стандартными острыми зондовыми датчиками Bruker SNL-10 (D) с паспортной жесткостью $0.06 \mathrm{~N} / \mathrm{m}$. Реальное значение жесткости каждого зонда определялось методом тепловых шумов, реализованным в программном обеспечении АСМ. Эксперименты с эритроцитами проводились с максимальной силой надавливания на уровне $500 \mathrm{pN}$, минимально возможной частотой сканирования $0.1 \mathrm{~Hz}$, амплитудой вертикального движения зонда в каждой точке измерения $1 \mu \mathrm{m}$, частотой движения по вертикали $250 \mathrm{~Hz}$. Как правило, линейный размер кадра АСМ данных составлял $15-20 \mu \mathrm{m}$.

Средние значения модуля Юнга эритроцитов определялись на АСМ изображениях, сглаженных фильтром, ослабляющим высокочастотные составляющие сигнала. Анализировался сигнал в центре клетки, внутри квадратной области размером приблизительно $2 \times 2 \mu \mathrm{m}$. Обработка АСМ данных осуществлялась в программных пакетах Nanoscope Analysis 1.50 и Gwyddion 2.41.

В инвертированном оптическом микроскопе эритроциты выглядят, как темные объекты круглой формы на фоне прозрачной подложки (рис. 1, $a$ ). Наблюдая эритроциты в течение нескольких часов, мы обнаружили, что некоторые из них после осаждения на подложку обесцвечиваются и становятся почти невидимыми (рис. $1, b$ ).

Согласно АСМ измерениям, в обоих случаях эритроциты не демонстрировали дисковидной двояковогнутой формы, присущей свободным, не прикрепленным к подложке клеткам. Темные клетки в исходном состоянии были плоскими, невысокими, $0.3 \pm 0.3 \mu \mathrm{m}(n=22)$, сильно распластанными по подложке и иногда имели небольшой бугорок вблизи центра (рис. 2,a,c). Трансформировавшиеся оптически прозрачные клетки становились значительно выше, $1.7 \pm 0.5 \mu \mathrm{m}(n=7)$, и имели выпуклую форму, близкую к полусферической (рис. $2, b, d)$. В среднем при измерении по данным АСМ топографии площадь проекции темных эритроцитов составила $44 \pm 8 \mu \mathrm{m}^{2}(n=18)$, у трансформировавшихся клеток этот параметр был $29 \pm 7 \mu \mathrm{m}^{2}(n=6)$. В ряде случаев у обесцвеченных эритроцитов ослаблялась адгезия к подложке, что обнаруживалось по откреплению клеток во время сканирования.

Неожиданным оказалось, что трансформация сопровождалась упрочнением эритроцитов. Средний модуль Юнга обесцвеченных эритроцитов был почти в 4 раза больше, чем у темных $48 \pm 10 \mathrm{kPa}(n=6)$ и $13 \pm 9 \mathrm{kPa}$ $(n=17)$ соответственно. Пример АСМ карт модуля Юнга эритроцитов в двух разных состояниях, а также гистограммы значений этого параметра представлены на рис. $2, e-h$.

Считается, что модуль Юнга измеряется точно, если объект индентируется, т.е. деформируется АСМ зондом, менее чем на десятую долю своей толщины [13]. Если это условие нарушается, измерения завышают модуль Юнга, проявляя близость твердой подложки. Темные эритроциты обладали малой высотой $0.3 \pm 0.3 \mu \mathrm{m}$ $(n=22)$, сопоставимой с деформацией $0.2 \pm 0.2 \mu \mathrm{m}$. Так как условие малой относительной деформации, очевидно, нарушено, результат $13 \pm 9 \mathrm{kPa}$ выше истинного значения модуля Юнга таких клеток. АСМ измерения велись с минимизированной пиковой силой, а значит и деформацией. В принципе, можно заметно уменьшить деформацию, заменив стандартный нанометрово-острый пирамидальный зонд на зонд со сглаженной сферической геометрией, с микронной или субмикронной коллоидной гранулой на кончике [14]. Исследования эритроцитов такими зондами планируются нами в будущем. Трансформировавшиеся эритроциты имели большую высоту $1.7 \pm 0.5 \mu \mathrm{m} \quad(n=7)$, что почти на порядок больше деформации. Следовательно, результат $48 \pm 10 \mathrm{kPa}$ достоверно характеризует модуль Юнга трансформировавшихся эритроцитов. Таким образом, значения модуля Юнга у темных эритроцитов завышены, а у обесцвеченных клеток измерены верно. В итоге наблюдается эффект как минимум четырехкратного упрочнения эритроцитов.

Анализируя литературные данные, можно отметить, что они сильно разнятся. Так, в АСМ исследовании 

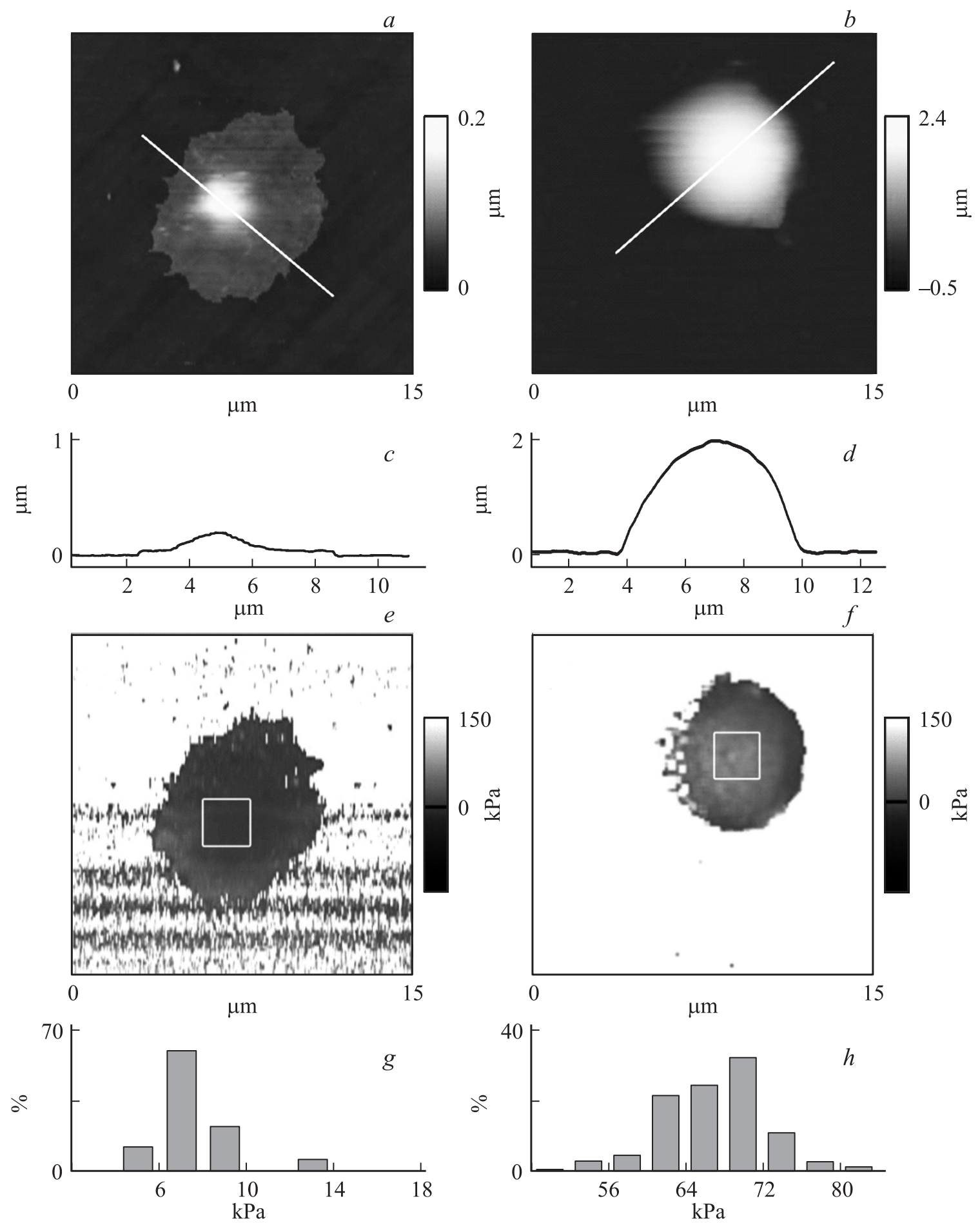

Рис. 2. Типичные данные АСМ исследования эритроцитов до/после трансформации. Тоновые изображения рельефа участков полилизиновой подложки с эритроцитом $(a) /(b)$; профили высоты $(c) /(d)$ вдоль сечений на изображениях $(a) /(b)$. Карты распределения модуля Юнга $(e) /(f)$, измеренные одновременно с изображениями $(a) /(b)$; гистограммы значений сигнала $(g) /(h)$, определенные внутри квадратных областей, отмеченных на изображениях $(e) /(f)$.

интактных эритроцитов [5] модуль Юнга был оценен в $16 \pm 2 \mathrm{kPa}$. Авторы [6,7] докладывали о значениях на уровне единиц килопаскалей, а в работе [8] сообщается о приблизительно 150 Ра. К несогласию в данных могут вести разные причины. В [5] определялся модуль Юнга эритроцитов крыс, а в [6-8] объектами исследования служили человеческие клетки. В [6,7] измеренные с помощью АСМ значения модуля Юнга эритроцитов человека по порядку величины совпадают, но оказываются ниже, чем у крысиных клеток. Особенно низкий модуль 
Юнга в [8], вероятно, есть результат использования не стандартных острых АСМ зондов, как в [5-7], а кантилевера со сферической частицей диаметром $4 \mu \mathrm{m}$ на кончике.

Как отмечалось, сила адгезии клеток с подложкой может существенно деформировать эритроциты. В исследованиях $[10,15]$ было замечено, что на подложках, обработанных раствором полилизина в концентрациях $100 \mu \mathrm{g} / \mathrm{ml}$, эритроциты меняли форму, а при концентрации $250 \mu \mathrm{g} / \mathrm{ml}$ происходил лизис клеток. В нашей работе брались на порядок меньшие концентрации полилизина, но отклонения формы эритроцитов от традиционной дисковидной двояковогнутой геометрии не исчезали.

Обесцвечивание эритроцитов ранее наблюдалось в работе [9]. Результат был связан с лизисом клеток после разрыва плазматической мембраны, продолжительное время растянутой на полилизиновой подложке с сильным адгезионным взаимодействием. Согласно расчетам, у распластанных на полилизине клеток величина натяжения мембраны составляет примерно $0.001 \mathrm{~N} / \mathrm{m}$ [9]. Это на порядок больше естественного натяжения, что могло вызывать разрыв мембраны и спонтанный лизис клетки. В нашем исследовании было обнаружено, что обесцвеченные эритроциты увеличивались в объеме и упрочнялись, но целостность мембраны сохранялась, и разрушения, т.е. лизиса трансформировавшихся клеток, не происходило. Эффект, скорее, отражает набухание клеток и, по-видимому, связан с истощением физиологического ресурса механочувствительных катионных каналов, ответственных за поддержание постоянства клеточного объема, и может быть вызван деградацией гемоглобина с образованием низко молекулярных димеров [16]. Близкий механизм обсуждался в работах $[17,18]$, где показано, что эритроциты животных, нокаутированных по белкам семейства Piezo, образующим механочувствительные катионные каналы, регулирующие клеточный объем, могут увеличиваться в объеме и понижать осмотическую устойчивость вследствие гипергидратации и in vitro, и in vivo. Индикатором такого понижения является рост внутриклеточного давления за счет поступления в эритроцит дополнительной жидкости, что отражается на значении модуля Юнга клетки. В конечном счете стрессовая стадия упрочнения и гипергидратации эритроцитов может привести к гемолизу. Мы получили дополнительные свидетельства в пользу упрочнения эритроцитов за счет гипергидратации. Оптические исследования показали, что трансформация закрепившихся на подложке эритроцитов развивалась примерно в 3 раза быстрее в гипотоническом (с пониженной в 1.5 раза тоничностью) растворе, чем в изотоническом.

Таким образом, в ходе проведенных оптических и АСМ экспериментов установлено влияние подложки и времени контакта с ней интактных эритроцитов на форму и модуль Юнга клеток. Обнаружено необратимое изменение состояния эритроцитов, продолжительное время (несколько часов) контактирующих с подложкой, обработанной раствором полилизина. Оно проявляется в том, что клетки приобретают полусферическую форму, уменьшают площадь контакта с подложкой и становятся тверже по сравнению с исходным распластанным и мягким состоянием. Причиной обнаруженной трансформации эритроцитов предполагается деградация гемоглобина вследствие его автоокисления с образованием низко молекулярных димеров [16]. Это может вызывать увеличение транспорта воды в клетку по осмотическому градиенту. Полученный результат представляется важным учитывать в АСМ исследованиях механических свойств не только интактных эритроцитов, но и других живых клеток.

Работа выполнена на оборудовании Центра коллективного пользования „Конфокальная микроскопия“ Института физиологии им. И.П. Павлова РАН. Работа поддержана грантом РНФ № 14-15-00677.

\section{Список литературы}

[1] Binnig G., Quate C.F., Gerber Ch. // Phys. Rev. Lett. 1986. Vol. 56. N 9. P. 930-933.

[2] Nowakowski R., Luckham P., Winlove P. // Biochim. Biophys. Acta. 2001. Vol. 1514. N 2. P. 170-176.

[3] Dulińska I., Targosz M., Strojny W., Lekka M., Czuba P., Balwierz W., Szymoński M. // J. Biochem. Biophys. Methods. 2006. Vol. 66. N 1-3. P. 1-11.

[4] Chen X., Feng L., Jin H., Feng S., Yu Y. // Clin. Hemorheol. Microcirc. 2009. Vol. 43. N 3. P. 243-251.

[5] Mozhanova A.A., Nurgazizov N.I., Bukharaev A.A. // Proceedings SPM-2003. Nizhni Novgorod. 2003. P. 266-267.

[6] Lekka M., Fornal M., Pyka-Fościak G., Lebed K., Wizner B., Grodzicki T., Styczeń J. // Biorheology. 2005. Vol. 42. N 4. P. 307-317.

[7] Maciaszek J.L., Andemariam B., Lykotrafitis G. // J. Strain Analysis. 2011. Vol. 46. N 5. P. 368-379.

[8] Rebelo L.M., Sousa J.S., Santiago T.M., Mendes Filho J. // Microscopy: advances in scientific research and education. 2014. Vol. 1. P. 141-152.

[9] Hategan A., Law R., Kahn S., Discher D.E. // Biophys J. 2003. Vol. 85. N 4. P. 2746-2759.

[10] Tuvia S., Almagor A., Bitler A., Levin S., Korenstein R., Yedgar S. // Proc. Natl. Acad. Sci. USA. 1997. Vol. 94. N 10. P. 5045-5049.

[11] Sneddon I.N. // Int. J. Eng. Sci. 1965. Vol. 3. N 1. P. 47-57.

[12] Khalisov M.M., Ankudinov A.V., Penniyaynen V.A., Dobrota D., Krylov B.V. // Act. Physiol. Hung. 2015. Vol. 102. N 2. P. $125-130$.

[13] Mathur A.B., Collinsworth A.M., Reichert W.M., Kraus W.E., Truskey G.A. // J. Biomech. 2001. Vol. 34. N 12. P. 1545-1553.

[14] Няпшаев И.А., Анкудинов А.В., Стовпяга А.В., Трофимова Е.Ю., Еропкин М.Ю. // ЖТФ. 2012. Т. 82. Вып. 10. C. $109-116$.

[15] Назаров П.Г., Берестовая Л.К. // ДАН. 1995. Т. 343. Вып. 1. С. 123-126.

[16] Mohanty J., Nagababu E., Rifkind J. // Front. Physiol. 2014. Vol. 5. P. 1-6.

[17] Faucherre A., Kissa K., Nargeot J., Mangoni M., Jopling Ch. // Haematologica. 2014. Vol. 99. N 1. P. 70-75.

[18] Cahalan S., Lukacs V., Ranade S., Chien S., Bandell M., Patapoutian A. // eLIFE. 2015. 4:e07370.DOI: 10.7554. P. $1-12$. 